\title{
Ambulatory blood pressure monitoring in elderly patients with chronic atrial fibrillation: is it absolutely contraindicated or a useful tool in clinical practice and research?
}

\author{
Valter Giantin ${ }^{1}$, Egle Perissinotto ${ }^{2}$, Alessandro Franchin $^{1}$, Kareen Baccaglini ${ }^{1}$, Francesca Attanasio ${ }^{1}$, \\ Monica Maselli ${ }^{1}$, Giorgia Grosso ${ }^{1}$, Maria Luisa Corradin ${ }^{1}$, Alessandra Tramontano ${ }^{1}$ and Enzo Manzato ${ }^{1}$
}

The aim of this study was to test whether ambulatory blood pressure monitoring (ABPM) in elderly patients with atrial fibrillation (AF) is as feasible and reliable as ABPM is in patients with normal sinus rhythm (SR). Studies of ABPM in the elderly remain limited, and the use of this method in patients with AF remains controversial. The Italian SIIA 2008 guidelines consider ABPM 'absolutely contraindicated' for AF patients. This study was conducted on 200 hospitalized patients aged $\geqslant 65$ years (68\% females; mean age $82.4 \pm 6.3$ years): 100 patients with SR and 100 patients with permanent AF. Each patient completed serial blood pressure (BP) measurements with a clinical sphygmomanometer (Sphyg) and ABPM. Differences in mean heart rate (HR) between patient groups were not statistically significant. A total of $99.5 \%$ of patients were hypertensive. There were no significant differences between SR and AF patients in mean systolic BP (SBP) and diastolic BP (DBP) values, as measured with the Sphyg or by ABPM. Compared with the Sphyg, errors associated with BP measurements obtained by ABPM did not significantly differ between the two groups. ABPM proved to be as feasible as Sphyg measurements in both AF patients (intraclass correlation coefficients $=0.73,0.67$ and 0.74 for SBP, DBP and HR, respectively) and SR patients (intraclass correlation coefficients $=0.74,0.58$ and 0.67 for SBP, DBP and HR, respectively). A Bland-Altman plot analysis confirmed that there was good agreement between the two methods. Stable AF (HR 60-100 b.p.m.) should not be considered as an absolute contraindication for the use of ABPM, even in the elderly; it could be a 'relative' contraindication for very unstable AF patients.

Hypertension Research (2013) 36, 889-894; doi:10.1038/hr.2013.65; published online 1 August 2013

Keywords: ABPM; atrial fibrillation; elderly patients

\section{INTRODUCTION}

Atrial fibrillation (AF) is the most common sustained arrhythmia presenting in clinical practice. Its pathogenesis is multifactorial, and its association with hypertension has been amply investigated and confirmed in the literature. ${ }^{1-5}$ The prevalence of hypertension and its impact on cardiovascular risk, especially in the elderly, requires the optimization of methods to diagnose and treat it. The variability of individuals' blood pressure (BP) values in old age makes it even more difficult to measure elderly AF patients' BP accurately; however, this is of fundamental importance because of the related risk of hypertensive and hypotensive episodes. ${ }^{6-8}$ Thus, valid devices for monitoring each patient's usual BP values in order to tailor their treatment are urgently needed. ${ }^{9}$

Single conventional BP readings using a mercury sphygmomanometer (Sphyg) fail to reflect around-the-clock BP variability; therefore, 24-h ABPM, that is, the repetitive, automated recording of BP levels over $24 \mathrm{~h}$ has become widespread in clinical practice. ${ }^{10-14}$ AF patients' irregular heart rate (HR) makes conventional auscultatory BP measurements difficult, and physicians' interpretation of Korotkoff sounds less consistent. It is also the reason that ABPM device used in these patients is often questioned. The latest SIIA (Italian Society for Hypertension) guidelines ${ }^{15}$ consider ABPM as absolutely contraindicated for cases of AF, frequent ectopic beats or other arrhythmias because it is assumed that ABPM is unable to record a regular series of heart beats, which calls into question this method's accuracy. The need to obtain a complete 24-h picture of a patient's BP for diagnostic and therapeutic purposes nonetheless leads physicians to consider using this method in AF patients as well, ${ }^{16-18}$ but the literature on this issue remains scant, especially for elderly patients.

We used ABPM to examine BP variations in patients aged $\geqslant 65$ years with permanent, stable AF (HR 60-100 b.p.m.) who were

${ }^{1}$ Geriatric Unit, Department of Medicine, University of Padua, Padova, Italy and ${ }^{2}$ Department of Cardiology, Thoracic and Vascular Sciences, University of Padua, Padova, Italy Correspondence: Dr F Attanasio, Geriatric Unit, Department of Medicine, University of Padua, via Giustiniani 2, 35100 Padova, Italy. E-mail: attanasio.doc@libero.it

Received 12 October 2012; revised 11 March 2013; accepted 28 March 2013; published online 1 August 2013 
hospitalized and admitted to our Geriatrics Division, and we compared the results with standard Riva-Rocci mercury Sphyg measurements to assess the feasibility of the automated device in patients with AF. A control group of patients with normal sinus rhythm (SR) was also examined to establish whether AF in elderly patients interfered with the feasibility of ABPM.

\section{METHODS}

\section{Study population}

This cross-sectional study was conducted using patients who were hospitalized in the Padua University Geriatrics Division from January 2008 to January 2011. At admission, the following data were recorded for each patient: personal details, anthropometric measurements, medical history related to hypertension and its treatment, any AF or other arrhythmias, cardiovascular risk factors and related conditions, for example, diabetes mellitus, obesity, dyslipidemia, cerebrovascular disease, atherosclerosis or dementia. While in the hospital, some patients underwent ABPM, mainly for uncontrolled hypertension, hypotension or for the purposes of reviewing their antihypertensive therapy. We consecutively enrolled 100 elderly patients with AF who exhibited a stable HR (between 60 and 100 b.p.m.) and 100 patients with a SR. All of the study participants in the AF group had a documented history of permanent AF (AF ongoing for a long time, for example, a year or more); during their stay in hospital, all patients had daily electrocardiograms recorded and printed routinely. During ABPM, casual measures of clinical BP with a mercury Sphyg and HR were registered (data not included for reasons of brevity).

The sample size of the present study would allow a power of $90 \%$ to detect a difference between the mean systolic BP (SBP) in AF and SR patients of $5 \mathrm{~mm} \mathrm{Hg}$, with a s.d. assumed of approximately $21 \mathrm{~mm} \mathrm{Hg}$ and a significance level of $5 \%$. A power of approximately $97 \%$ would be obtained by repeatedmeasures ANOVA to test the effect size of 0.32 for measurement methods (ABPM vs. Sphyg) and the effect size of 0.45 for patient group (AF vs. SR). Patients were selected considering their ability to stand and walk during ABPM. Obese and underweight patients (body mass index $>30$ or $<17 \mathrm{~kg} \mathrm{~m}^{-2}$ ), uncooperative patients with dementia or psychosis, terminally ill patients or those with advanced neoplastic disease or severe cardiovascular disease (for example, acute coronary syndrome, acute myocardial infarction or heart failure) were ruled out. AF and SR patients were matched on gender and age. Frequency matching was applied by matching at the level of participant gender and 5-year age-class strata. The proportion of women was $68 \%$ in both groups, and the mean age was $82.5 \pm 6.9$ and $82.3 \pm 5.9$ years in AF and SR patients, respectively.

Verbal informed consent was obtained from all patients in the presence of a witness (trained medical personnel) and was documented in the patient's clinical record.

\section{$A B P M$ and Sphyg readings}

The ABPM device (AND-TM-2430; Kitamoto Shi, Saitama, Japan) was handled by trained medical personnel, usually between the 3rd and 7th day after hospital admission to avoid stress-related reactions to hospitalization and enable patient stability. ABPM was calibrated using a standard mercury Sphyg, and a cuff appropriate to the subject's mid-upper arm circumference was used. The cuff was positioned on the dominant arm, according to the SIIA guidelines. ${ }^{15}$ The ABPM devices and Sphyg were positioned on the same arm. For ABPM positioning, three BP determinations were made, along with sphygmomanometric measurements to verify that the average of the two sets of values did not differ by $>5 \mathrm{~mm} \mathrm{Hg}$. The recorders were programmed to record $\mathrm{BP}$ at 15-min intervals during the day (0701-2200 hours) and at 20-min interval during the evening and the night (2201-0700 hours). Only absolute artifactual readings were removed from $\mathrm{ABPM}$ recordings according to the Italian and European Guidelines. The editing procedure was checked accordingly with the patient's diary. Monitoring was considered suitable for statistical analysis when satisfying the following criteria: at least $24 \mathrm{~h}$ of valid $\mathrm{BP}$ recording; at least 1 and 2 valid measurements per hour during the night and day, respectively, and at least $70 \%$ of the expected number of readings. ${ }^{10,15}$
The mean $24 \mathrm{~h}$ and daytime and nighttime SBP and diastolic BP (DBP) measurements were recorded. The mean $24 \mathrm{~h}$ HR was also recorded. The European Society of Cardiology-European Society of Hypertension cutoff ${ }^{19}$ was adopted for hypertension in 24-h ambulatory BP recordings ( $>125 /$ $80 \mathrm{~mm} \mathrm{Hg}$ ).

Sphyg measurements (Erkameter 300; Erka, Germany, a standard mercury device) were obtained by physicians for all patients at admission and between 0800 and 0900 hours during the hospital stay.

The clinical BP measurement procedure was performed according to the international guidelines as follows: ${ }^{11,19}$ the patient was seated at rest for at least 5 min before BP measurements. During the first visit, BP was measured in both arms to exclude significant inter/arm differences $(>20 \mathrm{~mm} \mathrm{Hg}$ for SBP or $>10 \mathrm{~mm} \mathrm{Hg}$ for DBP). If this occurred, the higher BP value was taken as the reference value. An appropriately sized cuff was placed around the arm at heart level, with the lower edge $2-3 \mathrm{~cm}$ above the point of brachial artery pulsation. Phase I (appearance) and V (disappearance) of the Korotkoff sounds were used to identify SBP and DBP, respectively. The clinical BP and HR measurements that were selected for statistical analysis were those that were obtained while patients were seated (conventionally, this is the measurement considered for the diagnosis of hypertension), and recorded in the patient's chart on the day before, the day after and the date when ABPM was initiated. For each patient, $\mathrm{BP}$ and HR measurements were also obtained via Sphyg and ABPM in sitting, lying and standing positions to measure orthostatic hypotension and evaluate agreement between the two sets of measurements.

\section{Statistical analysis}

All analyses were performed for either AF and SR patients separately or for the sample as a whole. The summary statistics include the mean \pm s.d. for quantitative variables, whereas frequencies and percentages were computed for qualitative variables. The Shapiro-Wilk test was used to test the normality of the distribution for the quantitative variables. When comparing the features of AF and SR patients, differences between the mean values were tested using unpaired Student's $t$-test or the Mann-Whitney test, as necessary, whereas differences in frequency distributions were evaluated using the $\chi^{2}$-test or Fisher's exact test, as applicable. When comparing within-group measurements obtained by ABPM and Sphyg, the differences between the mean values were verified using paired Student's $t$-test or the Wilcoxon signed-rank test, as appropriate, whereas differences in frequency distributions were evaluated using McNemar's test. The mean differences between the BP values obtained by the two methods within each group were expressed in terms of s.d. and $95 \%$ confidence intervals. A repeated-measures analysis of variance was applied to test the effect of the methods (within-group effects) and AF (between-group effects) and their interaction with the mean BP measurements.

To evaluate the reliability of the research methods, Shrout and Fleiss intraclass correlation coefficients were computed considering the methods as a fixed effect. The Bland-Altman approach was used to evaluate the level of agreement between the two methods in measuring each $\mathrm{BP}$ value. The degree of agreement was assessed by plotting the differences between ABPM and Sphyg measurements against the mean values obtained by the two methods. To graphically check whether the variability and bias were uniform over the entire range of measurements, the mean error and limits of agreement (mean \pm 2 s.d.) were included in these plots. An analysis of covariance was also used to assess the effect of AF on the relationship between the error and the dimension of the variable.

All analyses were performed using the SAS statistical software package, rel. 9.13 (SAS Institute, Cary, NC, USA). The level of statistical significance for each test was set to 0.05 .

\section{RESULTS}

The patients' clinical characteristics are summarized in Table 1 by patient group. In the SR group, patients were admitted for the following: syncope/presyncope $(n=49)$, cardiovascular disease $(n=9)$, cerebrovascular disease $(n=7)$, gastrointestinal disorders $(n=4)$, metabolic disorders $(n=11)$, accidental falls $(n=3)$, respiratory disorders $(n=11)$, uncontrolled diabetes $(n=4)$ and dehydration 
$(n=2)$. In the AF group, patients were admitted for the following: syncope/presyncope $(n=26)$, cardiovascular disease $(n=13)$, cerebrovascular disease $(n=5)$, gastrointestinal disorders $(n=7)$, metabolic disorders $(n=9)$, respiratory disorders $(n=30)$, dehydration $(n=3)$, renal failure $(n=1)$, infections $(n=5)$ and deep vein thrombosis $(n=1)$. The two groups appeared to be fairly homogeneous; no statistically significant differences in their clinical SBP, DBP and HR were observed. For SBP, inter-arm BP differences ranged between 10 and $20 \mathrm{~mm} \mathrm{Hg}$ in 26 patients and were $<10 \mathrm{~mm} \mathrm{Hg}$ in the remaining patients. For DBP, inter-arm differences were $<10$ $\mathrm{mm} \mathrm{Hg}$ in all patients. Data on BP measurements taken during lying and standing positions were not considered in the present study, but there was good agreement between the Sphyg and ABPM readings.

At admission, the HR in the AF group was higher than the SR group, but this was not statistically significant; HR was always well controlled and <100 b.p.m. (mean $78.7 \pm 16.3$ b.p.m.). Only the number of drugs taken showed a marginally significant difference between groups: AF patients took more drugs than SR controls $(2.1 \pm 1.2$ vs. $1.6 \pm 1.1, P=0.05)$. The mean proportion of successful ABPM measurements in SR patients was $93.4 \%$ (minimum $70 \%$, maximum $100 \%$ ) and in $\mathrm{AF}$ patients was $93.5 \%$ (minimum $70 \%$, maximum 100\%). The mean number of inflations was 98.37 (minimum 49; maximum 171).

Table 2 compares the BP measurements obtained by the two methods (Sphyg and ABPM) in the two patient groups (AF and SR). The BP values recorded with the Sphyg (in terms of absolute $\mathrm{mm} \mathrm{Hg}$ ) were higher than those measured using ABPM in both patient groups. The mean SBP, DBP and pulse pressure $(\mathrm{PP})$ values that were detected

Table 1 Baseline clinical characteristics, by patient group

\begin{tabular}{lccc}
\hline Clinical characteristics & $A F, \mathrm{~N}=100(50 \%)$ & $S R, \mathrm{~N}=100(50 \%)$ & $\mathrm{P}^{\mathrm{a}}$ \\
\hline Sex (F/M) & $68 / 32$ & $68 / 32$ & \\
Age (years) & $82.5 \pm 6.9$ & $82.3 \pm 5.9$ & \\
Hypertension (years) & $14.7 \pm 12.4$ & $9.5 \pm 8.4$ & 0.17 \\
Antihypertensive therapy (\%) & $86(88.9)$ & $81(81.2)$ & 0.27 \\
Therapy (\%) & $82(41)$ & $87(43.5)$ & 0.36 \\
Number of drugs & $2.1 \pm 1.2$ & $1.6 \pm 1.1$ & 0.05 \\
Systolic blood pressure (mm Hg) & $151.3 \pm 27.3$ & $156.5 \pm 28.5$ & 0.14 \\
Diastolic blood pressure (mm Hg) & $84.4 \pm 13.9$ & $85.0 \pm 13.2$ & 0.77 \\
Pulse pressure (mm Hg) & $67.0 \pm 19.7$ & $71.4 \pm 23.3$ & 0.08 \\
Heart rate (b.p.m.) & $78.7 \pm 16.3$ & $76.1 \pm 12.1$ & 0.20 \\
Smokers (\%) & $3(1.5)$ & $5(2.5)$ & 0.41 \\
Alcohol consumption (\%) & $22(11)$ & $15(7.5)$ & 0.19
\end{tabular}

Abbreviations: AF, atrial fibrillation; F, female; M, male; SR, sinus rhythm.

aThe comparison between the means was done with the unpaired Student's $t$-test, whereas the comparison between proportions was done with McNemar's test. by the Sphyg did not differ significantly between the two patient groups. Only the clinically recorded HR was significantly higher in the AF patients than SR patients $(77.0 \pm 9.6$ vs. $74.1 \pm 8.9, P=0.03)$. No differences were observed between the mean values (for BP and HR) of the two patient groups, as measured using ABPM. The significance of the effect of patient group and measurement method is given in the last two columns of Table 2; the two measurement methods generated significantly different mean values for SBP, DBP and HR $(P<0.0001)$. Only the PP exhibited no significant methodrelated differences $(P=0.88)$. A significant influence on $\mathrm{HR}$ was revealed only in AF patients, who obtained higher mean scores than SR patients $(P=0.05)$.

Table 3 quantifies the differences between the two methods for measuring each BP value by patient group, with the related limits of agreement. In both patient groups, only the mean difference between the PP obtained by the two methods was not statistically significant. For the other BP values, ABPM tended to significantly underestimate the Sphyg readings, although the method proved reliable, as shown by the intraclass correlation coefficients. No statistically significant differences emerged when the AF and SR patient groups were compared. Figure 1 shows the differences between the methods used to measure BP by patient group at the respective $95 \%$ confidence intervals. $\mathrm{ABPM}$ underestimates the mean $\mathrm{BP}$ values in $\mathrm{AF}$ and $\mathrm{SR}$ patients to the same extent. Figure 2 shows the results of the BlandAltman plot analysis used to represent the agreement between the two BP measuring methods: the mean of the differences gives an indication of the constant inaccuracy between the two methods. The analysis of covariance indicated that a systematic bias existed only

Table 3 Comparison between blood pressure measures recorded using ABPM and Sphyg, by patient group

\begin{tabular}{|c|c|c|c|c|c|}
\hline \multirow[b]{2}{*}{ Group } & \multicolumn{3}{|c|}{$D$ (ABPM-Sphyg) } & \multirow[b]{2}{*}{$I C C$} & \multirow[b]{2}{*}{ Limits of agreement } \\
\hline & Variable & Mean \pm s.d. & $\mathrm{t}$-testa & & \\
\hline \multirow[t]{4}{*}{ AF } & $\mathrm{SBP}(\mathrm{mm} \mathrm{Hg})$ & $-6.4 \pm 13.5$ & $<0.0001$ & 0.73 & $-33.4,20.6(\mathrm{~mm} \mathrm{Hg})$ \\
\hline & DBP (mm Hg) & $-6.0 \pm 8.6$ & $<0.0001$ & 0.67 & $-23.2,11.2(\mathrm{~mm} \mathrm{Hg})$ \\
\hline & PP (mm Hg) & $-0.3 \pm 9.7$ & 0.64 & 0.84 & $-19.7,18.9(\mathrm{~mm} \mathrm{Hg})$ \\
\hline & HR (b.p.m.) & $-2.8 \pm 7.2$ & 0.004 & 0.74 & -17.2, 11.6 (b.p.m.) \\
\hline \multirow[t]{4}{*}{ SR } & SBP (mm Hg) & $-6.4 \pm 13.5$ & $<0.0001$ & 0.74 & $-33.4,20.6(\mathrm{~mm} \mathrm{Hg})$ \\
\hline & DBP (mm Hg) & $-6.1 \pm 8.4$ & $<0.0001$ & 0.58 & $-22.9,10.3(\mathrm{~mm} \mathrm{Hg})$ \\
\hline & $\mathrm{PP}(\mathrm{mm} \mathrm{Hg})$ & $-0.2 \pm 10.5$ & 0.73 & 0.72 & $-21.2,20.8(\mathrm{~mm} \mathrm{Hg})$ \\
\hline & HR (b.p.m.) & $-1.9 \pm 7.4$ & 0.0002 & 0.67 & $-16.7,12.9$ (b.p.m.) \\
\hline
\end{tabular}

Abbreviations: ABPM, ambulatory blood pressure monitoring; AF, atrial fibrillation; DBP, diastolic blood pressure; HR, heart rate; ICC, intraclass correlation coefficient; PP, pulse pressure; SBP, systolic blood pressure; Sphyg, sphygmomanometer; SR, sinus rhythm. ${ }^{a}$ Comparison between ABPM and Sphyg measurements. The $P$-values were obtained by applying the paired $t$-test.

Table 2 Mean blood pressure values by measurement method and patient group

\begin{tabular}{|c|c|c|c|c|c|c|c|c|}
\hline & \multicolumn{3}{|c|}{ Sphygmomanometer } & \multicolumn{3}{|c|}{$A B P M$} & \multirow{2}{*}{$\begin{array}{c}\text { Method } \\
\mathrm{Pb}^{\mathrm{b}}\end{array}$} & \multirow{2}{*}{$\begin{array}{c}\text { Patient group ( } A F \text { vs. } S R \text { ) } \\
\mathrm{P}^{\mathrm{b}}\end{array}$} \\
\hline & $A F$ mean \pm s.d. & $S R$ mean \pm s.d. & $\mathrm{Pa}^{\mathrm{a}}$ & $A F$ mean \pm s.d. & $S R$ mean \pm s.d. & $\mathrm{Pa}^{\mathrm{a}}$ & & \\
\hline SBP $(\mathrm{mm} \mathrm{Hg})$ & $139.2 \pm 19.2$ & $139.3 \pm 19.0$ & 0.98 & $132.8 \pm 17.1$ & $132.9 \pm 18.3$ & 0.95 & $<0.0001$ & 0.97 \\
\hline DBP (mm Hg) & $78.4 \pm 11.8$ & $77.7 \pm 9.5$ & 0.66 & $72.4 \pm 9.3$ & $71.7 \pm 8.7$ & 0.55 & $<0.0001$ & 0.57 \\
\hline $\mathrm{PP}(\mathrm{mm} \mathrm{Hg})$ & $60.7 \pm 13.5$ & $61.5 \pm 15.1$ & 0.68 & $60.3 \pm 12.3$ & $61.3 \pm 12.7$ & 0.61 & 0.88 & 0.62 \\
\hline HR (b.p.m.) & $77.0 \pm 9.6$ & $74.1 \pm 8.9$ & 0.03 & $74.2 \pm 10.1$ & $72.2 \pm 9.1$ & 0.14 & $<0.0001$ & 0.05 \\
\hline
\end{tabular}

Abbreviations: AF, atrial fibrillation; DBP, diastolic blood pressure; HR, heart rate; PP, pulse pressure; SBP, systolic blood pressure; SR, sinus rhythm.

aComparison between AF and SR patients' mean values. The $P$-values were obtained by applying the unpaired $t$-test.

'Significance level for the effect of the method and the patient group on the differences, obtained by applying a general linear model. 


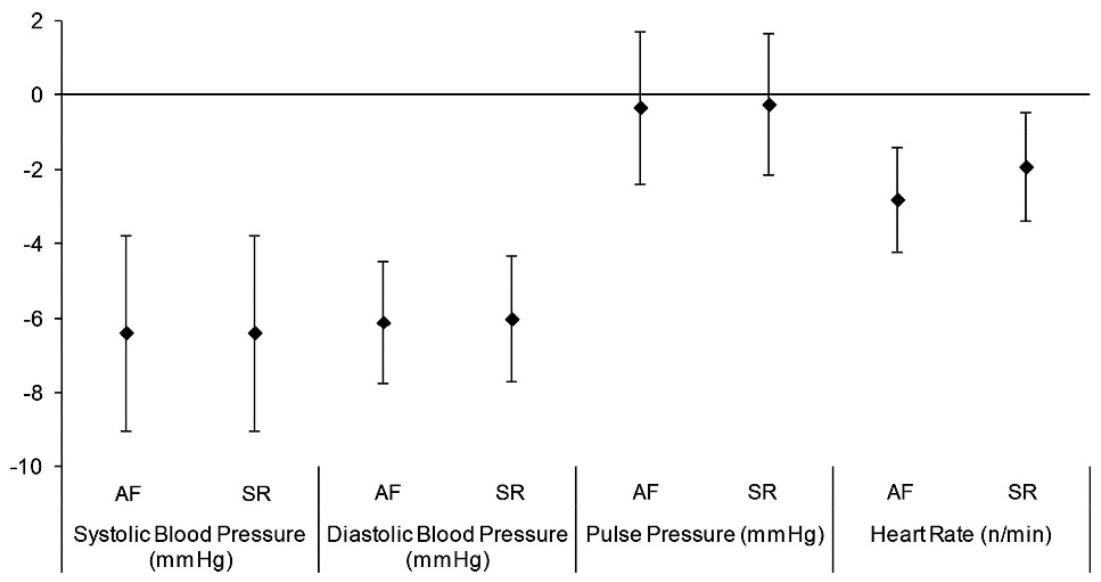

Figure 1 Pressure differences for the two measurement methods. Pressure differences for the two measurement methods (ABPM vs. Sphyg) by patient group. Vertical lines represent the 95\% confidence intervals. ABPM underestimates the mean BP values in AF and SR patients to the same extent.
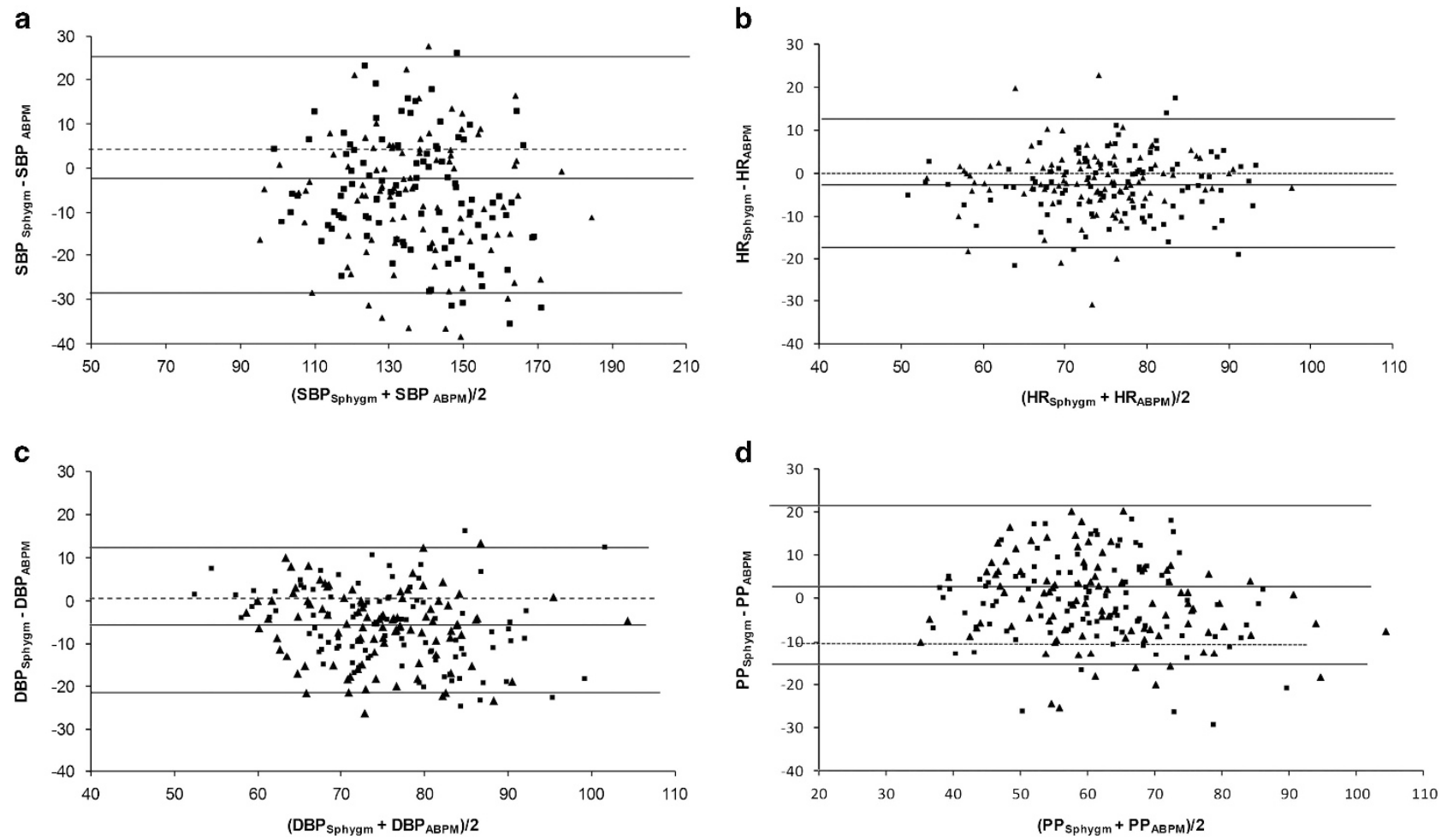

Figure 2 Agreement between the two BP measuring methods. A Bland-Altman plot is used to compare the different BP values (SBP, DBP and PP) (panels a, $\mathbf{c}$ and $\mathbf{d}$ respectively) and HR (panel b) values obtained with the Sphyg and by ABPM. Squares indicate measurements in AF patients, and triangles indicate measurements taken from SR patients. Plain lines indicate mean differences and the limits of agreement. The dotted lines represent the line of equality between the two methods. AF exhibited no statistically significant effect on any of the BP values in terms of modifying the measurement error relating to ABPM.

for DBP and PP and that ABPM underestimated these measures significantly more frequently at higher pressure values $(P=0.002$ and 0.006 , respectively). AF showed no statistically significant effect on any of the $\mathrm{BP}$ values in terms of modifying the measurement error related to ABPM (SBP, $P=0.95$; DBP, $P=0.83$; PP, $P=0.87$; and HR, $P=0.34)$.

\section{DISCUSSION}

The group of 200 patients admitted to the Geriatrics Division consisted of very elderly subjects whose mean age was $82 \pm 6$ years.
Two-thirds of the sample were women. Patients with AF are often hypertensive and carry a higher cardiovascular risk than non-AF patients. Arrhythmia has a negative impact on outcomes in terms of morbidity and survival, particularly in patients with hypertension or heart failure. ${ }^{18}$ This explains why most patients were taking polytherapy, especially among those with AF. The differences in the BP measurements obtained by ABPM and the Sphyg increased with age, although this age-related increment was less important than baseline high BP values. This phenomenon was also reported in the PAMELA study quoted in the European Hypertension Guidelines ${ }^{19}$ 
and in studies of the experimental use of $\mathrm{ABPM}^{11,15}$ in a younger outpatient population of 1651 subjects with a mean age of $46 \pm 12$ years (range 25-64). The mean daytime BP values obtained with ABPM were compared with the average of three BP measures obtained with the Sphyg and recorded on the patient's chart for three days, that is, the day before, the day after and the same day when ABPM was performed. This approach differs from the one adopted for most large clinical trials using $\mathrm{ABPM}^{14,16,20}$ in which the average of the three BP values obtained immediately before ABPM were used for comparison because the BP measurements served other research purposes (for example, epidemiological studies of cardiovascular risk or studies of the therapeutic effects of drugs) in ambulatory patients and inpatients. In addition, it would have been too complicated and expensive to measure patients' BP for 3 consecutive days. Our approach was motivated by the need to more accurately correlate patients' absolute BP values with the average daytime BP measured using ABPM. The average of three Sphyg measurements obtained immediately before applying the ABPM device is usually higher and correlates less well with the ABPM results. Especially in the elderly, applying the ABPM device may be alarming, whereas this is less likely for routine Sphyg measurements taken daily, at about the same time of day by a general practitioner.

Our findings confirm that ABPM provides reliable BP measurements, even though mean SBP, DBP and PP are systematically underestimated. The advantage of ABPM is that it reduces the impact of patient-operator interactions when the patient's BP is measured. ${ }^{21}$ Our results also confirm that the presence of stable AF (HR 60100 b.p.m.) in elderly patients does not affect the accuracy of ABPM results.

The main aim of our study, however, was to establish whether AF actually is a relative contraindication for the use of ABPM, as stated in the European Society of Hypertension recommendations for $\mathrm{BP}$ measurement, ${ }^{10}$ or even an 'absolute contraindication', as claimed by the latest SIIA guidelines regarding office, ambulatory and home BP monitoring. ${ }^{15}$ In the American Heart Association consensus document on Hypertension in the elderly, ${ }^{22}$ ABPM is considered feasible and reliable for elderly patients, and no limitations due to AF are established.

We found a systematic difference between the mean BP values obtained with Sphyg and those obtained by ABPM, but there were no significant differences between patients with and without AF, as shown in Figure 1. This result confirmed that ABPM is equally feasible for SR and AF patients. The differences in the detection of the AF and SR patients' baseline HR were not significant, despite its greater inherent variability in AF patients (as we can expect in the presence of an arrhythmia), but this was not true of the average clinical HR recorded in patients' charts $(P=0.03)$. The Bland-Altman plot analysis confirmed the homogeneity of the variance in the BP measurements obtained using the two methods in both AF and SR patients.

AF patients have so far been excluded from most ABPM studies, as well as from validation studies of ambulatory BP measuring devices. However, our work supports the findings of Lip et al., ${ }^{16}$ Olsen et al., ${ }^{17}$ Vázquez-Rodríguez et al. ${ }^{21}$ and other authors who state that automated 24-h ABPM may be used successfully in patients with AF. We support the opinion that ABPM should not be contraindicated in AF patients, particularly when validated class $\mathrm{A} / \mathrm{A}$ recorders are used. Our measurements in $\mathrm{AF}$ patients appear to be comparable to those obtained in SR patients, as found in other reports using smaller samples of AF patients who were a decade younger than our patient group. ${ }^{16,17}$
In recent years, many studies have focused on the application of ABPM to explore the relationship between hypertension and cardiovascular diseases. ${ }^{23,24}$ Studies of ABPM in AF patients before and after electric cardioversion ${ }^{25}$ have highlighted the efficacy of ABPM for new research fields, thanks to the additional information it provides, compared with single Sphyg measurements. These studies warrant further development in order to understand the effects of rhythm control on BP because they could potentially greatly have an impact on BP management in patients with AF and a history of hypertension.

Our study is not without limitations. ABPM was performed in hospitalized patients; therefore, the BP measurement data may differ from those of outpatients in fully ambulatory conditions. We could not assess the presence of permanent AF with a simultaneous electrocardiogram tape with ABPM; this protocol could be certainly applied in future studies and would be of value, especially in patients with paroxysmal AF. Nevertheless, the clinical history and repeated electrocardiograms allowed for the assessment of the presence of permanent AF with very high probability. Finally, no prospective follow-up was planned, and we did not systematically perform outpatient BP monitoring in the patients seen in the hospital. Additional studies are necessary to test the reproducibility of ABPM in the $\mathrm{AF}$ population, given that the literature surrounding this issue is insufficient.

In conclusion, we agree with the more permissive attitude of the European and American guidelines on hypertension ${ }^{19,22}$ and those specifically relating to $\mathrm{ABPM},{ }^{10}$ which state that $\mathrm{AF}$, particularly if it is stable (HR 60-100 b.p.m.), does not appear to contraindicate the use of ABPM. No studies of the use of ABPM when HR $>100$ / $<60$ b.p.m. have been conducted to date, and these cases should be carefully evaluated by the physicians in clinical practice. Some authors claim that BP measurements obtained with oscillometric devices may suffer from numerous artifacts due to highly variable HRs. This can be avoided by using modern recorders and pre-programmed monitoring settings to obtain the following: (1) a large number of measurements in a 24 -h period (every 15 or $20 \mathrm{~min}$ ) to increase the number of valid measurements per hour and (2) the automatic repetition of HR measurements above a certain preset 'range.' Moreover, considering ABPM as a standard method for BP monitoring makes it possible to improve BP control in elderly and frail patients and thereby reduce their global cardiovascular risk.

\section{CONFLICT OF INTEREST}

The authors declare no conflict of interest.

\section{ETHICAL APPROVAL}

Informed consent was obtained from all participants. The Local Ethics Committee has approved the research protocol.

1 Camm AJ, Kirchhof P, Lip GY, Schotten U, Savelieva I, Ernst S, Van Gelder IC Al-Attar N, Hindricks G, Prendergast B, Heidbuchel H, Alfieri O, Angelini A, Atar D, Colonna P, De Caterina R, De Sutter J, Goette A, Gorenek B, Heldal M, Hohloser SH, Kolh P, Le Heuzey JY, Ponikowski P, Rutten FH. Guidelines for the management of atrial fibrillation: the task force for the management of atrial fibrillation of the European Society of Cardiology (ESC). Eur Heart J 2010; 31: 2369-2429.

2 Andrews M, Nelson BP. Atrial fibrillation. Mt Sinai J Med 2006; 73: 482-492.

3 Friberg J, Buch P, Scharling H, Gadsbphioll N, Jensen GB. Rising rates of hospital admissions for atrial fibrillation. Epidemiology 2003; 14: 666-672.

4 Prystowsky EN, Benson DW Jr, Fuster V, Hart RG, Kay GN, Myerburg RJ, Naccarelli GV, Wyse DG. Management of patients with atrial fibrillation. A statement for healthcare professionals. from the Subcommittee on Electrocardiography and Electrophysiology, American Heart Association. Circulation 1996; 93: 1262-1277. 
5 Ciaroni S, Cuenoud L, Bloch A. Clinical study to investigate the predictive parameters for the onset of atrial fibrillation in patients with essential hypertension. Am Heart $J$ 2000; 139: 814-819.

6 Zito M, Parati G, Omboni S, Cervone C, Ulian L, D’Aviero M, Abate G, Mancia G. Effect of ageing on blood pressure variability. J Hypertens Suppl 1991; 9: S328-S329.

7 Bjorklund K, Lind L, Zethelius B, Berglund L, Lithell H. Prognostic significance of 24-h ambulatory blood pressure characteristics for cardiovascular morbidity in a population of elderly men. J Hypertens 2004; 22: 1691-1697.

8 Chaudhry SI, Krumholz HM, Foody JM. Systolic hypertension in older persons. JAMA 2004: 292: 1074-1080.

9 Fotherby MD, Potter JF. Twenty-four-hour ambulatory blood pressure in old and very old subjects. J Hypertens 1995; 13: 1742-1746.

10 O'Brien E, Asmar R, Beilin L, Imai Y, Mallion JM, Mancia G, Mengden T, Myers M, Padfield P, Palatini P, Parati G, Pickering T, Redon J, Staessen J, Stergiou G, Verdecchia P. European Society of Hypertension working group on blood pressure monitoring. European Society of Hypertension recommendations for conventional, ambulatory and home blood pressure measurement. J Hypertens 2003; 21: 821-848.

11 O'Brien E, Asmar R, Beilin L, Imai Y, Mancia G, Mengden T, Myers M, Padfield P, Palatini P, Parati G, Pickering T, Redon J, Staessen J, Stergiou G, Verdecchia P. European Society of Hypertension working group on blood pressure monitoring. Practice guidelines of the European Society of Hypertension for clinic, ambulatory and self blood pressure measurement. J Hypertens 2005; 23: 697-701.

12 O'Brien E. The circadian nuances of hypertension: a reappraisal of 24-h ambulatory blood pressure measurement in clinical practice. Ir J Med Sci 2007; 176: 55-63.

13 O'Brien E. Twenty-four-hour ambulatory blood pressure measurement in clinica practice and research: a critical review of a technique in need of implementation. J Intern Med 2011; 269: 478-495.

14 Dolan E, Stanton A, Thijs L, Hinedi K, Atkins N, McClory S, Den Hond E, McCormack $P$, Staessen JA, O'Brien E. Superiority of ambulatory over clinic blood pressure measurement in predicting mortality. Hypertension 2005; 46: 156-161.

15 Parati G, Omboni S, Palatini P, Rizzoni D, Bilo G, Valentini M, Agabiti-Rosei E, Mancia G. Italian Society of Hypertension Guidelines for conventional and automated blood pressure measurement in the office, at home and over 24 hours. High Blood Press Cardiovasc Prev 2008; 15: 283-310.

16 Lip GY, Zarifis J, Beevers DG. Ambulatory blood pressure monitoring in atrial fibrillation. Am J Cardiol 1996; 78: 350-353.

17 Olsen R, Amlie A, Omvik P. Twenty-four-hour blood pressure monitoring in atrial fibrillation. Blood Press Monit 2002; 7: 149-156.

18 Moubarak G, Messali A, Extramiana F, Leenhardt A. La fibrillation atriale est-elle un marqueur indépendant de risque cardio-vasculaire? (Is atrial fibrillation an independent marker of cardiovascular risk?). Ann Cardiol Angeiol 2010; 59: S14-S18.

19 Mancia G, De Backer G, Dominiczak A, Cifkova R, Fagard R, Germano G, Grassi G Heagerty AM, Kjeldsen SE, Laurent S, Narkiewicz K, Ruilope L, Rynkiewicz A, Schmieder RE, Boudier HA, Zanchetti A, Vahanian A, Camm J, De Caterina R, Dean V, Dickstein K, Filippatos G, Funck-Brentano C, Hellemans I, Kristensen SD, McGregor K, Sechtem U, Silber S, Tendera M, Widimsky P, Zamorano JL, Erdine S, Kiowski W, Agabiti-Rosei E, Ambrosioni E, Lindholm LH, Viigimaa M, Adamopoulos S, AgabitiRosei E, Ambrosioni E, Bertomeu V, Clement D, Erdine S, Farsang C, Gaita D, Lip G, Mallion JM, Manolis AJ, Nilsson PM, O'Brien E, Ponikowski P, Redon J, Ruschitzka F, Tamargo J, van Zwieten P, Waeber B, Williams B, Management of Arterial Hypertension of the European Society of Hypertension; European Society of Cardiology. 2007 Guidelines for the management of arterial hypertension: The task force for the management of arterial hypertension of the European Society of Hypertension (ESH) and of the European Society of Cardiology (ESC). J Hypertens 2007; 25: 1105-1187.

20 Burr ML, Dolan E, O'Brien EW, McCormack P. The value of ambulatory blood pressure in older adults: the Dublin outcome study. Age Ageing 2008; 37: 201-206.

21 Vázquez-Rodríguez B, Pita-Fernández S, Regueiro-López M, García-Pedreira D, CarroRodriguez MJ, Pérez-Rivas G, de la Iglesia-Martínez F. Concordance between automatic and manual recording of blood pressure depending on the absence or presence of atrial fibrillation. Am J Hypertens 2010; 23: 1089-1094.

22 Aronow WS, Fleg JL, Pepine CJ, Artinian NT, Bakris G, Brown AS, Ferdinand KC, Forciea MA, Frishman WH, Jaigobin C, Kostis JB, Mancia G, Oparil S, Ortiz E, Reisin E, Rich MW, Schocken DD, Weber MA, Wesley DJ. ACCF/AHA 2011 expert consensus document on hypertension in the elderly: a report of the American College of Cardiology Foundation Task Force on clinical expert consensus documents developed in collaboration with the American Academy of Neurology, American Geriatrics Society, American Society for Preventive Cardiology, American Society of Hypertension, American Society of Nephrology, Association of Black Cardiologists, and European Society of Hypertension. J Am Coll Cardiol 2011; 57: 2037-2114.

23 Uen S, Vetter H, Mengden T. Simultaneous recording of blood pressure and ST-segment with combined, triggered ambulatory 24-h devices. Blood Press Monit 2003; 8: 41-44.

24 Uen S, Asghari S, Nickenig G, Mengden T. Early morning surge and dipping status of blood pressure: are these of predictive value for silent myocardial ischemia? J Clin Hypertens 2009; 7: 351-357.

25 Sanders NA, Bertolone C, Jetter TL, Wasmund SL, Croci F, Solano A, Brignole M, Hamdan $\mathrm{MH}$. Restoring sinus rhythm results in blood pressure reduction in patients with persistent atrial fibrillation and a history of hypertension. J Cardiovasc Electrophysiol 2012; 23: 722-726. 